\title{
A Comparison of Management Conditions in Japan's Dental Clinics and Medical Clinics
}

\author{
Koichi Kawabuchi, Keiko Kajitani \\ Department of Health Care Economics, Division of Public Health, Graduate School of Medical and Dental Sciences, \\ Tokyo Medical and Dental University, Tokyo 113-8549, Japan \\ Correspondence e-mail to: kawabuchi.hce@tmd.ac.jp
}

\begin{abstract}
In recent years, national medical expenditures have continued to increase in Japan, and have now reached 39 trillion yen. In contrast, dental clinic expenditures have been slow to grow over the past few years, totaling 2.7 trillion yen. At the same time, the number of dentists continues to increase, with a total of 102,551 dentists in 2012, surpassing the 100,544 physicians at medical clinics. Objective: Given this, we compared management conditions at dental clinics and medical clinics over time to determine whether management conditions of dental clinics are really as harsh as often claimed. Methods: We used the relevant data provided in the Central Social Insurance Medical Council's Survey on Economic Conditions in Health Care for statistics, which depicts management conditions at clinics, and analyzed the causes. Results: Annual fluctuations in the revenue/expense gap (revenue less expense) show that the gap for dentists far undercut that for physicians at medical clinics. The main reason for this decline in revenue is that the number of dental patients declined more than the unit price rose compared to the medical clinic. Conclusion: We determined that management conditions are harsh for dental clinics.
\end{abstract}

Key words: added value, labor productivity, management conditions, profitability

\section{INTRODUCTION}

In recent years, national medical expenditures have continued to increase significantly in Japan, and are estimated to have reached 39.2 trillion yen in fiscal 2012. At this rate, national medical expenditures will breach the 40 trillion yen point soon. In contrast, dental clinic expenditures totaled 2.7 trillion yen, but their share in national medical expenditures has continued to drop every year, amounting to only $6.9 \%$ in fiscal $2012 .{ }^{1}$

While the management environment for the dental industry is severe, the number of dentists continues to increase, with the number of dentists employed at dental clinics reaching 102,551 as of December 31, 2012. This surpasses the 100,544 physicians at medical clinics, but the number of dental clinics has barely increased since 2004. Is this really because management conditions for dental clinics are worsening compared to medical clinics $?^{2}$ In order to examine this hypothesis, this paper compared management conditions for dental clinics and medical clinics and analyze some of the causes.

\section{METHODS}

We used the data provided in the last 16 Survey on Economic Conditions in Health Care (May 1976 to June 2011) carried out by the Central Social Insurance Medical Council almost every year. ${ }^{3}$ This survey provides a clear picture of management in the medical industry, and is carried out with the objective of providing basic information on social insurance medical fees. The facilities targeted in the survey are selected from medical facilities nationwide offering service eligible for coverage under social insurance using a stratified random sampling method (sampling rate: $1 / 50$ for dental clinics, $1 / 20$ for medical clinics).

Clinics run by non-individual were added to the survey's subject pool starting with the 1999 survey, but this report, as shown in Table 1, limits its purview to individual, which accounted for $84 \%$ of all clinics in 2010 . 
Table 1. Number of clinics

\begin{tabular}{llllllllllllllllll}
\hline Survey year & 1976 & 1981 & 1984 & 1987 & 1989 & 1991 & 1993 & 1995 & 1997 & 1999 & 2001 & 2003 & 2005 & 2007 & 2009 & 2011 \\
$\begin{array}{l}\text { Number of dental } \\
\text { clinics by individual }\end{array}$ & 69 & 186 & 298 & 601 & 562 & 576 & 623 & 618 & 662 & 585 & 586 & 544 & 615 & 593 & 551 & 391 \\
$\begin{array}{l}\text { Number of medical } \\
\text { clinics run by indi- } \\
\text { vidual without beds }\end{array}$ & 889 & 963 & 885 & 815 & 742 & 725 & 739 & 681 & 669 & 636 & 566 & 508 & 558 & 560 & 492 & 537 \\
\hline
\end{tabular}

We used the revenue/expense gap to explore management conditions, and focused on the changes in these indicators over time. "Revenue" as used here refers only to revenue for medical services provided to outpatients (medical insurance, publicly funded health care, pollution-related medical care, worker's compensation insurance, and services not covered by insurance), and does not include other medical revenue (revenue from preventative health care, revenue from medical consultations, and revenue from test referrals and document fees, among others). Nevertheless, in 1981 dental clinics did not have any items corresponding to "other medical revenue" and thus it is not excluded from revenue for medical services provided to outpatients. In contrast, expenses include salaries, pharmaceutical and material costs, outsourcing costs and depreciation, among others.

Moreover, medical clinics did not have the subcategories of clinics with beds and clinics without beds in 2009 and 2011, so medical clinics not including hospitalization fees were used instead.

Revenue and expenses in each survey year were corrected using the National Consumer Price Index ${ }^{1}$ (benchmark year of 2010) ${ }^{4}$ so that comparisons over time could be made on a real basis excluding the impact of price fluctuations. The National Consumer Price Index is a comprehensive index, which excludes fresh food, examines price trends for a wide range of goods in Japan and indexes the changes. The index was negative from 1999 as Japan suffered through a deflationary period, but in November 2013 inflation rose 1.2\% over the previous year, the highest level since $1.0 \%$ inflation in November 2008. This can be attributed to higher costs from the effect of a weak yen on gasoline prices, utility rates and other prices.

\section{RESULTS}

Annual fluctuations in the revenue/expense gap show that the gap for dentists always undercut that for physicians at medical clinics, with the exception of 1981 , and was approximately $30-40 \%$ lower on average. This is the main factor between the change in the management gap for medical clinics and dental clinics, which was generally 100: 100 , but reached 100 : 42 by fiscal 2012 .
These results are consistent with the previous research carried out by Ms. Tsuneishi and others. ${ }^{5}$ This research analyzed the Survey of Management of Dental Clinics carried out by the Japan Dental Association for the years 1998 through 2006.

So why does this management gap between dental clinics and medical clinics occur? As regards management conditions at dental clinics, previous study ${ }^{6}$ have already used the past nine editions of the same Survey on Economic Conditions in Health Care to report on fluctuations in revenue. This study attempted to clarify the different characteristics of dental clinics and medical clinics by adding new data and carrying out observations over the long term, as well as considering inflation growth. First, when considering the management characteristics of a medical facility, it is important to analyze in terms of the two factors of profitability and labor productivity. ${ }^{7}$ We used the per diem unit price per outpatient as the indicator for profitability and the number of patients seen per day by a dentist or physician at medical clinics for labor productivity. The product of these two indicators results in the revenue per day per dentist or physician ${ }^{8,9}$

Figure 1 compared the annual fluctuations in revenue per day per dentist or physician at medical clinics (the data for physicians is from 1981 since clinics were not sub-categorized into clinics with beds and from 1976 for dentists). Since the number of service days, the number of dentists and the number of outpatients was not noted in 2009 and 2011, data could not be plotted for this period.

When we compare the data on a real basis in 2007 , we find that revenue per day totaled approximately 224,000 yen per physician at medical clinic. In contrast, revenue per day was about 124,000 yen per dentist -about half of that for physicians.

It is particularly interesting to note that revenue per day per dentist trended the 100,000-150,000 yen range for the thirty-year period from 1976 to 2007, while in contrast, revenue per day for physicians climbed in real terms from 150,000 yen to the 250,000 yen range during the same period.

Next, we analyzed the causes of changes in revenue for physicians and dentists. Figure 2 shows that the number of patients seen per day per dentist fell from 21.7 to 18.5 


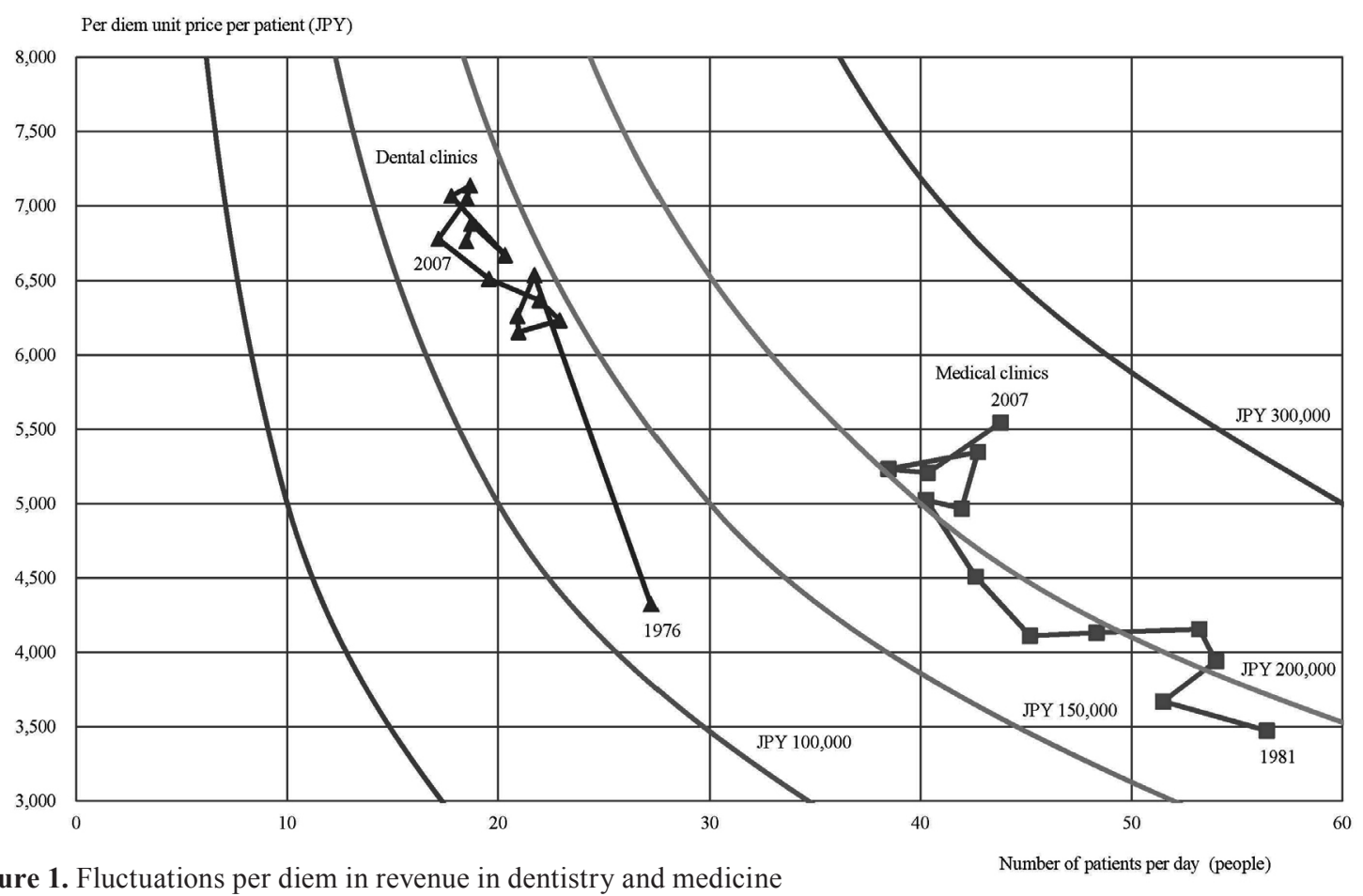

Figure 1. Fluctuations per diem in revenue in dentistry and medicine

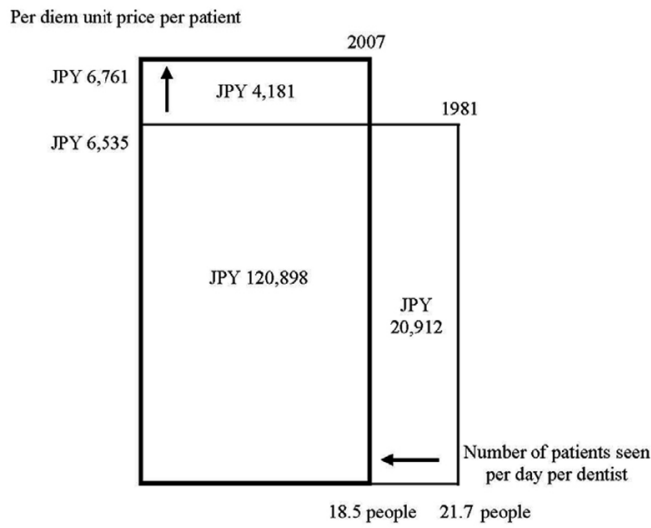

Dental clinics

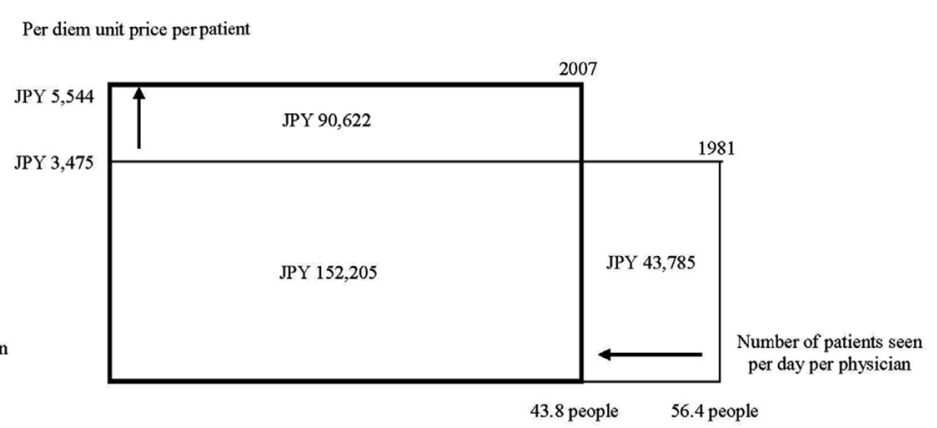

Medical clinics (without beds)

Figure 2. Causal analysis of per diem revenue in dentistry and medicine

from 1981 to 2007 , resulting in a 20,912 yen $(6,535$ yen per patient $\times-3.2$ people) reduction in revenue. At the same time, the per diem unit price per patient rose from 6,535 yen to 6,761 yen, but this only translated into a 4,181 yen increase in revenue. If we subtract the two, we find that revenue decreased 16,731 yen, indicating that the rise in unit prices was not enough to cover the negative impact of a decline in the number of patients treated.

In contrast, revenue totaled 195,990 yen in 1981 for physicians, but the number of patients seen per day per physician declined from 56.4 to 43.8 , resulting in a 43,785 yen reduction in revenue $(3,475$ yen per patient $x$
-12.6 people). At the same time, the per diem unit price per patient rose from 3,475 yen to 5,544 yen, resulting in a 90,622 yen increase in revenue. This amounted to a net gain of 46,837 yen, bringing revenue to 242,827 yen in 2007. The impact of the reduced number of patients treated could be adequately covered for physicians by the rise in the unit price.

\section{DISCUSSION}

Indeed, the final report of the 2012 Economic Census for Business Activity, released by the Ministry of Internal Affairs and Communications and the Ministry 
of Economy, Trade and Industry in August 2013, showed that the number of employees working in hospitals and medical clinics (medical practitioners) ranked at the top. This census was essentially a census of companies. The number of employees was highest in the elderly welfare and nursing sector, at 1,790,000, accounting for $3.2 \%$ of all industries. This was followed by hospitals, in second place with 1,750,000 employees, and medical clinics (medical practitioners), ranked eighth with 910,000 employees. In contrast, dental clinics came in at 29th place, with 404,000 employees. Hospitals account for $3.2 \%$ of total employees in industries and medical clinics for $1.6 \%$, while dental clinics account for only $0.7 \%$ of employees.

At the same time, added value, which indicates the profit by a company in one year, totaled 8.1 trillion yen for hospitals, putting them at the top, while medical clinics had the sixth highest profit. However, dental clinics were in 49th place. Added value refers to sales (revenues) less expenses and is calculated by adding back in salaries and taxes. It indicates the ability to return the value generated in business activities to shareholders (investors), employees, the national government and local governments. At first glance, it would seem that the medical industry has a strong capacity to generate social value.

However, if we look at added value per employee (excluding foreign companies), the medical industry does not fare well compared to other industries. While added value per employee is only 5,310,000 yen for medical clinics and 5,170,000 yen for hospitals, it is $16,560,000$ yen for banks and 12,350,000 yen for life insurers. In contrast, it is 3,960,000 yen for dental clinics, less than three-fourths that of medical clinics.

According to statistics from the Ministry of Health, Labor and Welfare, the total number of dentists has continued to increase, exceeding 100,000 in 2010 and standing at 102,551 as of December 31,2012 . The number of dentists at medical facilities per 100,000 people has continued to increase every year since reaching the 70 range in 2002, and totaled 78.210 years later in 2012. This indicates that an environment has been established in which adequate medical care can be provided. The Survey of Dental Diseases has been carried out every six years since 1957 with the aim of ascertaining the condition of dental care in Japan and obtaining basic materials needed to promote dental care measures in the future. According to the most recent survey (conducted in November 2011), 38.3\% of the population are 8020 achievers (the percentage of the population that had 20 or more teeth at age 80 ), up from $24.1 \%$ in the previous survey (2005). ${ }^{1}$ Moreover, the percentage of $\mathrm{DMFT}^{2}$ (decayed, missing and filled

\footnotetext{
http://www.8020zaidan.or.jp/index.html (In Japanese)

b DMFT index equals to total DMF teeth of all insured people divided by number of insured people. (provided by the World Dental Federation's Special Dental Statistics Committee)
}

teeth) by age declined across the board. These results were possible precisely because adequate dental care was provided on the back of plentiful manpower. At the same time, the negative aspects of this saturated environment for management comes into stark relief. The number of dental clinics has reached 68,474 (as of October 1, 2012, according to the Survey on Medical Facilities), which is higher than the number of convenient stores in the same month $(46,365)$, a comparison that is often used (Japan Franchise Association). As a result, competition between dentists intensified nationwide, and management conditions deteriorated every year, with a growing number of dental clinics forced to close (bankruptcy). In particular, in Tokyo dental clinics close at a pace of one a day. For this reason, a growing number of dental clinics are open on Sundays and evenings to try to halt their deteriorating earnings. In a 2009 survey of dental clinics in Tokyo carried out by the Tokyo Dental Care Association, only $7 \%$ of respondents said that they would encourage their own children to become dentists, down sharply from $23 \%$ in 1983 , when the survey began.

\section{CONCLUSION}

This paper compared management conditions between dental clinics and medical clinics. The results showed that dental clinics face harsh conditions. In the medium to long term, dental service compensation would have to be raised by increasing unit prices and expanding services eligible for insurance coverage. Moreover, the dentist supply and demand also needs to be corrected, Nonetheless, in the short term, dentists will have to address these issues on their own ${ }^{10}$, given Japan's tough fiscal situation. Revenue from sources other than insurance as a percentage of a clinic's revenue over the past 10 years was $3.5-5.6 \%$ for medical clinics, but higher for dentists $(10.5-13.1 \%) .{ }^{11}$ This show that services not covered by insurance are important for dentists. Dental clinics will need to be managed with an approach based on more scientific data.

\section{REFERENCES}

1. Health, Labour and Welfare Statistics Association. Fiscal 2010 National Medical Expenditures by Statistics and Information Department, Ministry of Health, Labour and Welfare. 2012.

2. Nishimura S. A consideration of dental care in the twenty-first century: problems with dental clinic management. Dent Med Res. 2001;21:31-5.

3. Central Social Insurance Medical Council. Survey on Economic Conditions in Health Care (Survey on Health Care Facilities). 1976, 1981, 1984, 1987, 1989, 1991, 1993, 1995, 1997, 1999, 2001, 2003, 2005, 2007, 2009, 2011. 
4. National Statistics Center, Statistics Bureau, Ministry of Internal Affairs and Communications [Internet]. Results of Fiscal 2010 Consumer Price Index (CPI) Survey. Available from: http://www. stat.go.jp/data/cpi/1.htm

5. Tsuneishi M, Hirata S, Yamamoto $T$, Ishii $T$. Analysis of the survey of management of dental clinics conducted by Japan Dental Association. Jpn J Dent Pract Adm. 2008;43:175-83.

6. Yamada R, Igarashi I, Teraoka K, Kawabuchi $\mathrm{K}$. Temporal change in revenue and expenses in dentistry and medicine. Jpn J Dent Pract Adm. 2002;37:200-12.

7. Kawabuchi K. Hospital management for the future. Tokyo: Igaku-Shoin; 1993. p. 132-5.
8. Kotler P, Clarke R. Marketing for health care organizations. New Jersey: Prentice Hall; 1987. p. 298-301.

9. Tsuneishi M, Yamamoto T, Ishii T. Income and expenditure in private dental clinics in Japan. Jpn Dent Sci Rev. 2013;49:100-5.

10. Vujicic M, Lazar V, Wall TP, Munson B. An analysis of dentists' incomes, 1996-2009. J Am Dent Assoc. 2012;143:452-60.

11. Igarashi I. Socioeconomic determinants of the choice of publicly uninsured dental service. Jpn J Dent Pract Adm. 2009;2:85-97.

(Received August 4, 2015; Accepted August 15, 2015) 